\title{
Exocrine Pancreatic Cancer pTis TNM Finding v8
}

National Cancer Institute

\section{Source}

National Cancer Institute. Exocrine Pancreatic Cancer pT is TNM Finding v8. NCI

Thesaurus. Code C134888.

Exocrine pancreatic cancer with a finding of carcinoma in situ. This includes high-grade pancreatic intraepithelial neoplasia (Panln-3), intraductal papillary mucinous neoplasm with high-grade dysplasia, intraductal tubulopapillary neoplasm with high-grade dysplasia, and mucinous cystic neoplasm with high-grade dysplasia. (from AJCC 8th Ed.) 